\title{
Sebaceous Carcinoma
}

National Cancer Institute

\section{Source}

National Cancer Institute. Sebaceous Carcinoma. NCI Thesaurus. Code C40310.

An adenocarcinoma with sebaceous differentiation. It presents as a painless mass and it may be multifocal. It grows in the ocular adnexae and in the skin of head and neck, trunk, genitals, and extremities. It is characterized by the presence of malignant cells with multivesicular and clear cytoplasm. It may recur and metastasize. 